\title{
A descriptive study of social development in family groups of rats (Rattus norvegicus)
}

\author{
DAVID R. DREWS, KENNETH J. FORAND, TODD G. GIPE, \\ LYNN D. CHELLEL, and ROBERT L. GAY, JR. \\ Juniata College, Huntingdon, Pennsylvania 16652
}

The social interactions of three family groups of rats (Rattus norvegicus) were observed daily when the litters were $25-32,60-67$, and 79-86 days old. In contrast to similar recent studies, fathers were present in these families. The data were analyzed to isolate the development of patterns of behavior specific to different age-sex classes. These data indicate frequent interactions between adult males and their young and suggest that the role of adult males in socialization of young deserves further attention.

Although a large amount of work has been done on the development of social behavior in Rattus norvegicus, most available studies are experimental in nature and focused on the ontogeny of one or a small number of particular behaviors. Thus, considerable attention has been directed to topics such as the effects of social isolation on later sexual (e.g., Gruendel \& Arnold, 1969), agonistic (e.g., Johnson, DeSisto, \& Koenig, 1972), and affiliative (e.g., Latané, Nesbitt, Eckman, \& Rodin, 1972) behavior.

Noting the value of such studies, Bekoff (1977) has pointed out the further need for nonexperimental descriptive research. Such studies, allowing for the normal development of social systems and recording a broad array of behaviors, are necessary not only for a better understanding of the processes occurring in the field, but also as an interpretive backdrop for more experimental work. Some such studies do exist. But the earlier ones (e.g., Barnett, 1958; Calhoun, 1962; Steiniger, 1950), although done in settings complex enough to have considerable ecological validity, tend to paint qualitative rather than quantitative pictures of social development. Later studies (Meany \& Stewart, 1979, 1981; Poole \& Fish, 1976) have been more quantitative but focus only on litters and their mothers without any adult males present. While mother-young interactions may be crucial to the socialization process, there is no clear rationale for ignoring what may be a significant role for fathers.

The present study was therefore undertaken to provide descriptive quantitative data on the development of social behaviors in a setting that included litters and both of their parents.

We would like to thank W. Jeffrey Burroughs for his helpful advice and criticism. Reprint requests should be sent to David R. Drews, Psychology Department, Juniata College, Huntingdon, Pennsylvania 16652. K. Forand is now at the University of Georgia, Athens, Georgia 30602. T. Gipe is now at Florida Institute of Technology, Melbourne, Florida 32901.

\section{METHOD}

\section{Subjects}

Three family groups of albino rats of the Wistar strain were purchased from Rockland Farms. All groups were composed of a mated pair and one litter. One litter contained two males and three females. Another contained two males and five females. And one was composed of one female and five males. In this litter, though, one of the males died shortly after the first observation cycle. On arrival, the young were 16 days old.

Each animal was marked with gentian violet stain to permit individual identification. Further handling occurred only when it was necessary to darken fading markings. Each family was then placed in a separate seminaturalistic environment.

\section{Apparatus}

The three identical environments consisted of a circular corrugated aluminum wall $(173 \mathrm{~cm}$ diameter $\times 92 \mathrm{~cm}$ high) that rested on a floor of hardware cloth. Two roofed nest boxes, open at either end, and several wooden blocks of various sizes were scattered through the enclosure. Paper towels were provided periodically for use as nesting material. Ad-lib laboratory chow was scattered on the floor, and water was continuously available from drinking tubes protruding through the wall at three evenly spaced locations.

A $24-\mathrm{h}$ timer controlled a $60-\mathrm{W}$ light on a $14 / 10$-h lightdark cycle, with the dark phase beginning at $1700 \mathrm{~h}$. Observations, all during the dark phase, were aided by two $25-\mathrm{W}$ red lights.

\section{Activities Recorded}

Behavioral categories used in the present study were groom, wrestle, box, pin, chase, mount, and threat. Definitions for these behaviors, excepting wrestle and threat, may be found in Drews and Wulczyn (1975). Wrestling resembles fighting, but lacks biting and audible vocalization. Threat was recorded when one rat showed piloerection, arched its back, and approached another in a sideways fashion, although its head continued to be oriented directly toward the recipient.

Initiators and recipients of each behavior were noted, as were winners and losers of wrestling and boxing encounters. Wrestling losers either assumed a supine submissive posture or showed active escape behavior, and the first animal in a boxing encounter to return to all four feet was regarded the loser.

A general index of sociability, total interactions initiated, was created by adding all of the cases in which a given individual initiated any of the activities noted above. 
Procedure

Prior to gathering any of the data reported here, observers were trained until in terobserver agreement reached $80 \%$. Periodic checks always yielded at least $\mathbf{8 0 \%}$ agreement, with an average of $90 \%$.

Data were gathered in three 8-day observation cycles, beginning when the litters were 25,60 , and 79 days old. On each night of each observation cycle, $2 \mathrm{~h}$ of data were collected on each family between 1700 and $2300 \mathrm{~h}$. Starting times, on the hour, were chosen randomly, with the restriction that they not run consecutively on a given environment. This procedure yielded $48 \mathrm{~h}$ of data on each family.

Between observation cycles, animals were undisturbed except for normal maintenance, occasional re-marking, and the removal of new litters within 2 days of parturition.

\section{RESULTS}

For analysis, data were combined across families and analyzed as a function of age-sex classes. Following Gartlan's (1968) suggestions for the analysis of social roles, comparisons were made within each sex across ages (adults vs. young) and within each age across sex. Chi square with Yates' correction (Siegel, 1956) was used to compare the observed frequency of each behavior with the frequency expected if the behavior had been distributed across the age-sex class by chance. Table 1 presents a summary of significant differences for each age-sex comparison for each observation cycle.

\section{Grooming}

For the adults, grooming was the modal behavior throughout the study, except for the last observation cycle, when adult males mounted and chased more than they groomed. Grooming became the modal behavior for the young in the last two cycles.

In the first cycle, adults of both sexes groomed more than the young of either sex, but by Cycle 2, grooming was sex rather than age related, with males the primary groomers. By Cycle 3, young males groomed less than the adult males or their female siblings. In contrast to the changeability of grooming patterns, aduIt females were the most frequent recipients in each cycle.

\section{Wrestling}

Through Cycle 2, wrestling was the modal behavior for the young. Adults wrestled significantly less often, and almost exclusively with their young. The most interesting changes over time had to do with sex patterns within the young. For the first two cycles, young males initiated more bouts than young females and were more likely recipients in Cycle 2. In Cycle 3, though, young males wrestled approximately $25 \%$ as frequently as they had in Cycle 2, whereas young females showed little change in their wrestling. This made the females both more frequent initiators and more frequent recipients.

Over the course of the study, 55\% of all wrestling encounters had discernible winners and losers. Using only these bouts, the percentage of wins in each agesex class remained relatively stable over time. Adult males won 72\%, 90\%, and 90\% (Cycles 1, 2, and 3, respectively) of their wrestling bouts, whereas young males won $61 \%, 54 \%$, and $62 \%$ of theirs. Females, on the other hand, were less successful. Young females won $40 \%, 45 \%$, and $39 \%$ of their bouts, whereas adult females won $23 \%, 33 \%$, and $21 \%$ of theirs.

\section{Boxing}

Relatively rare throughout, few age-sex patterns emerged. Most notably, young females boxed more than young males in Cycle 3. Across all cycles, boxing encounters produced discernible winners and losers $41 \%$ of the time. Using only these bouts, adult males were consistently successful, winning $100 \%$ in Cycles 1 and 3 and $90 \%$ in Cycle 2. Young males were less successful over time, dropping from $62 \%$ to $49 \%$ to $29 \%$. Adult females won $0 \%, 50 \%$, and $50 \%$ of their bouts, and young females won $41 \%, 37 \%$, and $62 \%$. Wonlost records for boxing thus do not resemble those

Table 1

Summary of Significant Behavioral Differences Between Age-Sex Classes in Each Age Period (Age of Young)

\begin{tabular}{|c|c|c|c|}
\hline \multirow{2}{*}{$\begin{array}{l}\text { Age-Sex } \\
\text { Class }\end{array}$} & \multicolumn{3}{|c|}{ Age Period } \\
\hline & 25-32 Days & 60-67 Days & 79-86 Days \\
\hline $\begin{array}{l}\mathrm{AM}>\mathrm{AF} \\
\mathrm{AM}>\mathrm{YM}\end{array}$ & $\begin{array}{l}\text { WR*,P**,TII } \dagger \\
\text { GR } \dagger\end{array}$ & $\begin{array}{l}\mathrm{GR}^{*}, \mathrm{~B}^{* *}, \mathrm{CH} \dagger, \mathrm{M} \dagger, \mathrm{TII} \dagger \\
\mathrm{M} \dagger\end{array}$ & $\begin{array}{l}\mathrm{WR} * *, \mathrm{P} \dagger, \mathrm{CH} \dagger, \mathrm{M} \dagger, \mathrm{TII} \dagger \\
\mathrm{GR} \dagger, \mathrm{CH} \dagger, \mathrm{M} \dagger, \mathrm{TII} \dagger\end{array}$ \\
\hline $\begin{array}{l}\mathrm{AF}>\mathrm{AM} \\
\mathrm{AF}>\mathrm{YF}\end{array}$ & $\begin{array}{l}\mathrm{GRD}^{* *}, \mathrm{PD} \mathbf{D}^{* *} \\
\mathrm{GR} \dagger, \mathrm{GRD} \dagger\end{array}$ & $\begin{array}{l}\mathrm{GRD} \dagger, \mathrm{WRD} \dagger, \mathrm{PD} \dagger, \mathrm{CHD} *, \mathrm{MD} * * \\
\mathrm{GRD} \dagger\end{array}$ & $\begin{array}{l}\text { GRD } \dagger, P^{*}, M^{*} \\
\text { GRD } \dagger\end{array}$ \\
\hline $\begin{array}{l}\text { YM }>\text { AM } \\
\text { YM }>\text { YF }\end{array}$ & $\begin{array}{l}\text { WR } \dagger, \text { WRD } \dagger, \mathrm{PD}^{*}, \mathrm{CH}^{*} \\
\mathrm{WR}^{*}, \mathrm{P} \dagger, \mathrm{TII} \dagger\end{array}$ & $\begin{array}{l}\mathrm{GRD} \dagger, \mathrm{WR} \dagger, \mathrm{WRD} \dagger, \mathrm{BD} *, \mathrm{P} \dagger, \mathrm{PD} \dagger, \mathrm{CHD} * *, \mathrm{TII} \dagger \\
\mathrm{GR}^{*}, \mathrm{GRD} \dagger, \mathrm{WR} \dagger, \mathrm{WRD} *, \mathrm{CH}^{* *}, \mathrm{M}^{* *}, \mathrm{TII} \dagger\end{array}$ & $\begin{array}{l}\mathrm{TH}^{*} \\
\mathrm{P} \dagger, \mathrm{M} \dagger, \mathrm{TH} \dagger, \mathrm{THD} *\end{array}$ \\
\hline $\begin{array}{l}\text { YF }>\text { AF } \\
\text { YF }>\text { YM }\end{array}$ & $\mathrm{WR} \dagger, \mathrm{WRD} \dagger$ & $\begin{array}{l}\mathrm{WR} \dagger, \mathrm{B}^{* *}, \mathrm{BD} *, \mathrm{P} \dagger, \mathrm{CH} \dagger, \mathrm{CHD} * *, \mathrm{TII} \dagger \\
\mathrm{CHD} * *\end{array}$ & $\begin{array}{l}\mathrm{WR} \dagger, \mathrm{WRD} \dagger, \mathrm{B} *, \mathrm{P} \dagger, \mathrm{CH} \dagger, \mathrm{CHD} \dagger, \mathrm{MD} \dagger, \mathrm{TII} \dagger \\
\mathrm{GR} \dagger, \mathrm{WR} * *, \mathrm{WRD} \dagger, \mathrm{B} \dagger, \mathrm{CHD} \dagger, \mathrm{MD} \dagger, \mathrm{TII} *\end{array}$ \\
\hline
\end{tabular}

Note $-A M=$ adult male,$A F=$ adult female, $Y M=$ young male,$Y F=$ young female,$G R=$ groomer,$G R D=$ groomed,$W R=$ wrestler, $W R D=$ wrestled, $B=$ boxer,$B D=$ boxed,$P=$ pinner,$P D=$ pinned, $C H=$ chaser, $C H D=$ chased, $T H=$ threat,$T H D=$ threatened, $T I I=$ total interactions initiated. $\quad{ }^{*} p<.05 . \quad{ }^{* *} p<.01 . \quad t p<.001$. 
for wrestling, except in the case of the consistently successful adult males.

\section{Pinning}

In Cycle 1, pinning was sex related, with males pinning more than females within age classes. This pattern reversed in Cycle 2, with young of each sex pinning more than their adult counterparts. Cycle 3 showed another reversal, back to the patterns of Cycle 1, although here young females also pinned more than adult females. Throughout the study, adult females were pinned more than adult males.

Meany and Stewart (1981) presented data indicating that, within litters, rankings based on frequency of pinning became relatively stable at about 46-50 days of age. Our data failed to show such stability. Even between 60-67 and 79-86 days, there were frequent changes in the rankings of males based on this measure.

\section{Chasing}

Chasing increased throughout the study. While young females chased more than adult females, chasing was primarily a male activity and, by Cycle 3 , primarily an adult male activity. All age-sex classes were equally likely to be chased in Cycle 1, the young were the most likely targets in Cycle 2, and the young females were the most frequently chased by Cycle 3 .

\section{Mounting}

As with chasing, mounting increased across cycles, was primarily a male-initiated activity, and, by Cycle 3 , was dominated by adult males, who mounted more than young males by a ratio approaching $7: 1$. The expected sex differences in being mounted appeared in Cycle 2, and by Cycle 3 , there was a dramatic age difference as well, with young females mounted far more often than adult females.

\section{Threat}

Only two threats were seen in the first two cycles, both performed by young males and directed at young males. Still rare in Cycle 3, most threats were made by and directed at young males.

\section{Total Interactions Initiated}

Within age classes, males were more likely to initiate interactions than females were in Cycle 1. This general pattern continued into Cycle 2, in which an age difference also emerged, such that within each sex, young initiated more interactions than adults. By Cycle 3, though, patterns of interaction came to be dominated by the adult males and the young females.

\section{Behavioral Profiles}

If the mean frequency of each behavior is computed for each age-sex class, it is reasonable to regard the resulting set of means as a behavioral profile of that age-sex class. Correlation coefficients calculated by treating each mean as a case, then, provide indexes of the similarity of different age-sex profiles or indexes of the stability of a profile over time within a given age-sex class. Total interactions initiated were omitted from these calculations.

Table 2 presents intercorrelations for comparisons of age-sex classes during each observation cycle. In Cycle 1, it is clear that age was the crucial determinant of the profile. Within each age class, the profiles of each sex were highly similar, whereas the profiles between ages were not. By Cycle 2, profiles of males and females began to diverge and the profile of the adult females resembled those of both young males and females, whose profiles continued to be highly similar. The only change in Cycle 3 resulted from a decrease in the similarity between the profiles of young males and young females.

When profiles within age-sex classes were compared across cycles, only adult females showed a highly stable profile over time such that the profile of each cycle correlated significantly with that of every other cycle. Young males and females each had significantly correlated profiles only between adjacent cycles, and the profiles of adult males were even less stable.

\section{DISCUSSION}

While the present data replicate and extend a number of the findings of earlier research, they also suggest some qualifications.

At the most general level, characterizations of rat societies as amicable (Barnett, 1958; Calhoun, 1962; Lore \& Flannelly, 1977; Steiniger, 1950) appear sound. We observed no serious fighting and found no wounds or scars on any animals as we removed them and inspected their pelage and skin at the end of the study.

Our data are also compatible with findings that argue that juvenile behavior grades into adult behavior with almost no topographic changes. Thus the distinction between juvenile and

Table 2

Intercorrelations of Mean Behavior Profiles Between Age-Sex Classes Within Each Age Period

\begin{tabular}{|c|c|c|c|c|c|c|c|c|c|}
\hline \multirow{2}{*}{$\begin{array}{c}\text { Age-Sex } \\
\text { Class }\end{array}$} & \multicolumn{3}{|c|}{ 25-32 Days } & \multicolumn{3}{|c|}{ 60-67 Days } & \multicolumn{3}{|c|}{ 79-86 Days } \\
\hline & $\mathrm{AM}$ & $\mathrm{AF}$ & YM & AM & $\mathrm{AF}$ & YM & $\mathrm{AM}$ & $\mathrm{AF}$ & YM \\
\hline $\begin{array}{l}\text { AF } \\
\text { YM } \\
\text { YF }\end{array}$ & $\begin{array}{l}.849 \dagger \\
.398 \\
.392\end{array}$ & $\begin{array}{l}.324 \\
.446\end{array}$ & $.958 \dagger$ & $\begin{array}{l}.436 \\
.514 \\
.421\end{array}$ & $\begin{array}{l}.667 * \\
.694^{*}\end{array}$ & $.916 \dagger$ & $\begin{array}{r}.159 \\
.400 \\
-.050\end{array}$ & $\begin{array}{l}.899 \dagger \\
.663^{*}\end{array}$ & .520 \\
\hline
\end{tabular}

Note $-A M=$ adult male, $A F=$ adult female $; M=$ young male, $Y F=$ young female. $\quad{ }^{*} p<.05 . \quad$ tp $<.01$. 
adult behavior depends not on the form of the behavior, but on the relative frequencies of particular behaviors (Meany \& Stewart, 1981; Poole \& Fish, 1976).

Data on the age of emergence of several behaviors distinguish our findings from those of Meany and Stewart (1981) and Poole and Fish (1976). In comparing males and females, for example, they argued that juvenile males are more social and initiate more rough-and-tumble play than females. Meany and Stewart (1979) found the same differences in rats 180-200 days old. Our data on wrestling and total interaction are consistent with this notion only through 60-67 days. By 79-86 days, young females wrestled more, boxed more, and initiated more social interactions than the young males.

Other differences emerge in looking more closely at the young males. Meany and Stewart (1981) noted a large number of changes beginning at about 40 days. Mounting and chasing increased rapidly, stable rank order hierarchies based on pinning began to emerge, threats increased, and the relative frequencies of boxing and wrestling changed so that boxing became the more frequently observed behavior. The changes in sexual behavior are consistent with expectations based on the physiological maturation of reproductive systems in females (e.g., Kragt \& Ganong, 1968) and in males (e.g., Sachs \& Meisel, 1979). The changes in the relative frequencies of boxing and wrestling are reasonably expected to coincide with the emergence of stable hierarchies, given the descriptions of Barnett (1958) and Calhoun (1962), which regard boxing as an early component in dominancerelated contests. While we did find dramatic increases in both mounting and chasing, juvenile males were responsible for a small proportion of the increase. Stable hierarchies did not develop. Threats increased, but only by $79-86$ days old, and wrestling remained more frequent than boxing throughout the study.

It seems possible to summarize these differences by suggesting that our juvenile males were slower to make the transition from juvenile to adult behavior. The presence of adult males may be at least partially responsible. For example, it is reasonable to expect that the transition of boxing and wrestling from play to dominance-related behavior (Poole \& Fish, 1976) might be slowed by the presence of an adult male who consistently wins such encounters. Similarly, adult sexual behavior might be slow to emerge in a setting in which a large adult male accounts for a dramatic majority of mounting. The hypothesis advanced here that adult males delay the onset of adult behavior in juvenile males is also compatible with Calhoun's (1962) more qualitative data and deserves more detailed examination.

The value of descriptive data is tied to the ecological validity of the settings in which they are gathered. An important consideration in this regard is the age-sex mix. At this point, there appears to be considerable uncertainty about the groupings that naturally occur in the field (Calhoun, 1962; Lore \& Flannelly, 1977; Steiniger, 1950). Nevertheless, it is unlikely that rats are socialized in the absence of adult males. While one might question the likelihood of fathers remaining with their young as long as in the present study, our setting is probably closer to ones obtaining in the field than are those that exclude all adult males.
Moreover, the fact that our adult males initiated more interactions with the young than the adult females did suggests that the males may play a substantial role in the socialization of young and that further study of their role is needed.

\section{REFERENCES}

Barnetr, S. A. An analysis of social behavior in wild rats. Proceedings of the Zoological Society of London, 1958, 130, 107-152.

BekofF, M. Socialization in mammals with an emphasis on non-primates. In S. Chevalier-Skolnikoff \& F. E. Poirier (Eds.), Primate bio-social development. New York: Garland, 1977.

CAlhoun, J. B. The ecology and sociology of the Norway rat. Bethesda, Md: U.S. Department of Health, Education, and Welfare-Public Health Service, 1962.

Drews, D. R., \& WulCZYN, F. H. Measuring dominance in rats. Psychological Record, 1975, 25, 573-581.

Gartlan, J. S. Structure and function in primate society. Folia Primatologica, 1968, 8, 89-120.

Gruendel, A. D., \& Arnold, W. J. Effects of early social deprivation on reproductive behavior of male rats. Journal of Comparative and Physiological Psychology, 1969, 67, 123-128.

Johnson, R. N., DeSisto, M. J., \& Koenig, A. B. Social and developmental experience and inter-specific aggression in rats. Journal of Comparative and Physiological Psychology, 1972, 79, 237-242.

Kragt, C. L., \& Ganong, W. F. Pituitary FSH content in female rats at various ages. Endocrinology, 1968, 82, 1241-1244.

Latané, B., Nesbitt, P., Eckman, J., \& Rodin, J. Long and short term social deprivation and sociability in rats. Journal of Comparative and Physiological Psychology, 1972, 79, 69-79.

Lore, R., \& Flannelly, W. Rat societies. Scientific American, 1977, 26, 106-118.

Meany, M. J., \& Stewart, J. Environmental factors influencing the affiliative behavior of male and female rats (Rattus norvegicus). Animal Learning \& Behavior, 1979, 7, 397-405.

Meany, M. J., \& Stewart, J. A descriptive study of social development in rats (Rattus norvegicus). Animal Behaviour, 1981, 29, 34-45.

Poole, T. B., \& Fish, J. An investigation of individual, age, and sexual differences in the play of Rattus norvegicus (Mammalia: Rodentia). Journal of the Zoological Society of London, 1976, 179, 249-260.

SaChs, B. D., \& Meisel, R. L. Pubertal development of penile reflexes and copulation in male rats. Psychoneuroendocrinology, 1979, 4, 287-296.

SIEgel, S. Nonparametric statistics for the behavioral sciences. New York: McGraw-Hill, 1956.

Steiniger, F. Zur Sociologie und sonstigen Biologie der Wanderratte. Zeitschrift für Tierpsychologie, 1950, 21, 356-379.

(Received for publication December 7, 1981.) 